\title{
Mechanisms Leading to Negative Transfer
}

\author{
Xiaorong Luo \\ Foreign Language School, Changchun University of Science and Technology, Changchun, China \\ Email: 1xrlinda301@yahoo.com.cn \\ Jian Gao \\ English Department, the Educational Institute of Jilin Province, Changchun, China \\ Email:bobgao1965@yahoo.cm.cn
}

\begin{abstract}
Negative transfer or interference is one of the difficulties in the course of second language learning for its existence in different linguistic levels. It is covered and permeable. At the same time, it is embodied in such various activities of parole as listening, speaking, reading, writing and translating and often occurs unconsciously when learners transfer items and structures that are not the same in both languages, and within the theory of contrastive analysis, it is believed that the greater the differences between the two languages, the more negative transfer can be expected. There are many factors that may lead to the negative transfer. The devices for it can be analyzed in the following aspects.
\end{abstract}

Index Terms - mechanism, negative transfer, language, semiotics, information theory

\section{The AsPect OF LANGUAGE ITSELF}

A language is a system of signs expressing ideas and transmitting information. In the course of the form and development of languages, each language has its own principles, rules and regulations to organize the language to communicate. The form of the linguistic rules is objective, once the rules are accepted by a language community, it has its own protecting function, which is stable and unique.

In second language learning, when the rules of the two languages contact, it is likely for their own protecting functions to resist. Two results might be caused when one language rules try to conquer the ones of another language: (1) positive transfer or negative transfer when learners apply the knowledge and skills of their native to the second language; (2) on the contrary, when the second language rules conquer the learners' native language, the linguistic proficiency of the second language learners' has enabled him/her to overcome the negative transfer. It is evident for the beginner to transfer their own language rules to the second language because the protecting function of their mother tongue has rooted in learners' mind. Interference occurs easily at the beginning of second language learning because learner's native language rules always try to make the rule of the second language suitable to the ones of their native language.

\section{THE ASPECT OF PSYCHOLOGY}

Psycholinguistics is the study of the mental structures and processes involved in the acquisition and use of language. Some theorists reconceptualized transfer within a cognitive framework, which was begun by Larry Selinker. In his formulation of interlanguage theory he identified language transfer as one of the mental process responsible for fossilization. Subsequently, there has been widespread acknowledgement that second language learners depend on their native language (L1) in forming interlanguage hypotheses. Learners do not construct rules in a vacuum; rather they work with whatever information is at their disposal. This includes knowledge of their L1. The L1 can be viewed as a kind of input from the inside. According to this view, "transfer is not 'interference', but a cognitive process"(Ellis, 2000,p52).In this aspect, the term "transfer" is a psychological one.

Cognitive theory can account for the fact that differences between the target language and native language do not always result in learning difficulty. A cognitive theory of language acquisition sees linguistic knowledge as the same as in kind other types of knowledge, and views the strategies responsible for its development as general in nature, related to and involved in other kinds of learning. In cognitivist position language transfer is regarded as a cognitive process, that is, second language (L2) learners make strategic use of their L1 in the process of L2 learning. "The use of L1 in L2 learning comes to be seen as an element of learning strategies"(Wang ,2007,p5). As Corder (1981) suggested that the learner's L1 may facilitate the developmental process of learning a L2 by helping him to progress more rapidly along the 'universal' route when the L1 is similar to the L2. And Krashen (1981) thought that learners can use the L1 to initiate utterances when they do not have sufficient acquired knowledge of the target language for this purpose. Both Corder's and Krashen's proposals refer to L1 as a learning "strategy". Only when learners' knowledge of the target language is not enough and need to make up for it or when learners believe that they may make use of their native language to infer the features of the target language, learners would transfer their L1. Therefore, language transfer is a cognitive means to use the knowledge of their native language for the second language learners. 


\section{THE ASPECT OF INFORMATION THEORY}

According to Longman dictionary, information theory explains how communication systems carry information and which measures the amount of information according to how much choice is involved when we send information. "One well-known model describes communication as a process consisting of the following elements: the information source, i.e. a speaker, selects a desired message out of a possible set of messages. The transmitter changes the messages into a signal which is sent over the communication channel it is received by the receiver and changed back into a message which is sent to the destination. In the process of transmission certain unwanted additions to the signal may occur which are not part of the message and these are referred to as noise. The information content of a unit is measured according to how likely it is to occur in a particular communication. The more predictable a unit is, the less information it is said to carry. The unit of information used in information theory is the binary digit or bit. The related concept of redundancy refers to the degree to which a message contains more information than is needed for it to be understood" (Longman Dictionary, 2005, p, 332).

From the content of the information theory, we can see that linguistic communication is a process of exchanging information, which can be expressed in the model below:

Context

Information

Speaker ----------------- $\rightarrow$ Hearer

Contact/Exposure

Code

In this model, there are six elements governing the communicative process. The firs element is "information", then goes to the "speaker and hearer" and the "contact" between the speaker and the hearer. The sending and receiving of the information can be realized through the "code switching", which is a change by a speaker or writer from one language or language variety to another one. Code switching can take place in a conversation when one speaker uses one language and the other speaker answers in a different language. A person may start speaking one language and then change to another one in the middle of their speech, or sometimes even in the middle of a sentence. Code switching can be a sign of cultural solidarity or distance or serve as an act of identity. This is the fifth element governing the communicative process. And the last is the "context", occurring before or after a word, a phrase or even a longer utterance or a text. The context often helps in understanding the particular meaning of the word, phrase, etc. The context also may be a broader social situation in which a linguistic item is used. Influenced by the context and the communicators (i.e. the speaker and the hearer), the messages can not be sent exactly to the hearer sometimes, this is called the "information gap".

Encoding and decoding in the same way, the communicators with the identical cultural background and language can communicate freely, for they share the same linguistic system rules. On the contrary, the exchanging information can not be realized in the same way that the communicators expect if they do not have the same cultural background and speak the same language, i.e. if the speaker and the hearer cannot share the identical linguistic system rules. The information carries the speaker's intended meaning when it is sent by the speaker. Actually, the speaker encodes and sends the information under his/her own cultural background. There is a code switching process when the information is sent to the hearer, during which the decoding process is influenced by the hearer's cultural background. In brief, the information encoded in one culture must be decoded in another culture because both the speaker and the hearer do not share the same cultural background. Under such circumstances, the informative content carried by the original code can not be accepted by the hearer equivalently, then the information gap will occur, leading to communicative failure, i.e. interference will occur. The information gap may be divided into the following types:

(1) After the hearer accepts and decodes the information, the meaning carried by the information has been added, for example: Shall we have a cup of coffee? This has the meaning of inviting someone to have a cup of coffee in both Chinese and English. English speaking people invite someone to have coffee together without intending to pay the bill for the others, but as for Chinese, the sentence means that the inviter pays the bill. Chinese grants more meaning to it than English. We call it value-added information.

(2) Opposite to (1), when the hearer's meaning is less than the speaker's, the information is decreased. We call it information dissipation/impairment. This results from the fact that the speaker's meaning has been beyond the literal meaning, transmitting the implied meaning with cultural element. We might hear:

"That guy's got a Midas touch"( He, 2005, p.219)

To understand the utterance, we must know what "Midas touch" is. It comes from a Greek tale "The Golden Touch." Midas is the king's name. However, even if we know that Midas touch is the Golden touch, we still cannot get the hang of the utterance above: how come the guy has got a Golden touch? As a matter of fact, the utterance was about business activity. The speaker was talking about that guy's skill in doing business: he gains a lot without great effort, as if he got a golden touch, like Midas.

(3) The information may be mistaken by the hearer while decoding, i.e. supposing one information is another. We might hear:

"The organization quickly mushroomed into a mass movement"(He,2005, p.221).

When we translate this into Chinese, the "bamboo" is often used instead of mushroom because Chinese and English 
take cognizance of different things according to their own cultural customs. As a result, the "mushroom" might be understood as "bamboo shoots", with the meaning that something appears and grows quickly. It is pity that such information is not exact because "mushroom" in English also means vanish or disappear quickly, though both of them mean numerals and growing fast, for example, mushroom fame, a mushroom millionaire, but Chinese "yuhouchunsun" has no such subtle meaning.

The hearer can not understand the speaker's meaning completely, which is called "decoding delay." Figurative meaning in different languages may have different associations. In cross-cultural communication, we must see what images of them can be brought about, and what context should be considered to grasp the exact meaning of words and expressions from one language to another. For instance, "You chicken!" he cried, looking at Tom with contempt. English native speaker compares the coward to a chicken, there is no such expression in Chinese, so Chinese learners of English often feel puzzled or confused about it because they never realized that the coward is the chicken in English.

In brief, conveying the information is constrained by culture. Based on this fact, the so-called "decoding" is a process of decoding the culture.

\section{THE ASPECT OF THE RELATIONSHIP BETWEEN LANGUAGE AND CULTURE}

Culture can be approached from different perspectives and consequently defined in quite different ways. "Culture can be, in a broad sense, understood as the total way of life of a nation, their approach to life and their ways of behaving, particularly living and thinking. This simple, but inclusive definition of culture implies that culture covers virtually all the aspects of human life and their correspondent behaviour, linguistic and nonlinguistic, such as traditions, conventions, social norms, customs, social habits, modes of living, patterns of thinking, beliefs, values and language.” (Chen, 2004, p, 276).

Culture is often bound up with language and thought, which are interdependent. A nation's culture and language often symbolize the nation's spirit and mind. Language and culture are closely related to and dependent on each other throughout their history. The native language is acquired with the ways, attitudes and patterns of behaving of the social group and these ways, attitudes and behaving patterns find their expression through language. Language and culture evolved and developed together, and therefore have been interwoven and mutually dependent throughout their history. Neither of them can exist or develop without the other.

\section{CONCLUSION}

In order to overcome the negative transfer from L1, in the aspect of language itself, learners have to master the standard pronunciation, accurate grammatical rules and vocabulary of the target language. When second language learners' linguistic knowledge increases, their linguistic competence increases, too. As for as the information theory and the cultural and linguistic relationships are concerned, learners have to improve their cultural quality of the target language because language and culture interact. Learning a language, in fact, is inseparable from learning its culture. So language and culture must be studied together, and great efforts must be made in the study of the culture in which the TL operates. Improving our cultural quality may make our language fluent, vivid, and elegant.

\section{REFERENCES}

[1] Chen Linhua. (2004). An introduction to linguistics. Changchun: Jilin University Press.

[2] Corder, S. P. (1981). Errors analysis and interlanguage. Oxford: Oxford University Press.

[3] He Ziran. (2005). Notes on pragmatics. Nanjing: Nanjing Normal University Press.

[4] Krashen, Stephen. (1981). Second language acquisition and second language learning. Oxford: Pergamon Press.

[5] Lado, R. (1957). Linguistics across cultures: Applied linguistics for language teachers. Ann Arbor, Michigan: University of Michigan.

[6] Longman dictionary of language teaching and applied linguistics. (2005). Beijing: Foreign Language Teaching and Research Press. 84,332.

[7] Rod Ellis, R. (1999). Understanding second language acquisition. Shanghai: Shanghai Foreign Language Education Press.

[8] Rod Ellis, R. (2000). Second Language Acquisition. Shanghai: Shanghai Foreign Language Education Press.

[9] Selinker, L. (1972). Interlanguage. International Review of Applied Linguistics, 10: 209-31.

[10] Wang Dongjin. (2007). Language Transfer And The Acquisition Of English Light-Verb And Noun Collocations By Chinese Learners. Msaster's thesis, Chonfqing University.

Xiaorong Luo was born in Changchun, China in 1963. She received her M.A. degree in linguistics from Changchun University of Science and Technology, China in 2009.

She is currently an associate professor in School of Foreign Languages, Changchun University of Science and Technology. Her interests are concerning the fields of language teaching and applied linguistics. She has published some papers relating to her teaching. 
Jian Gao was born in Changchun, China in 1965. He got his bachelor degree in English teaching from Siping Teachers' College, Siping, Jilin, China in 1984.

$\mathrm{He}$ is currently an associate professor in English Department, the Educational Institute of Jilin province, China. His favorite fields are the general linguistics and teaching methodology. His latest publication is The importance of Teaching English Phonetics, and he also did the project on the differences of Chinese and English Phonetics. 